\title{
The male circumcision: the oldest ancient procedure, its past, present and future roles
}

\author{
MASUMBUKO Y. MWASHAMBWA ${ }^{1 *}$, IPYANA H. MWAMPAGATWA ${ }^{1}$, ALEXANDER RASTEGAEV $^{1}$ and AINORY \\ P. GESASE ${ }^{2}$ \\ ${ }^{1}$ Department of Surgery and Maternal Health, College of Health Sciences, University of Dodoma, P. O Box 395, \\ Dodoma, Tanzania \\ ${ }^{2}$ Department of Biomedical Sciences, University of Dodoma, Dodoma, Tanzania
}

\begin{abstract}
Circumcision, a surgical removal of male prepuce has existed throughout human history, and it appears it shall exist until humanity ends. During its entire existence, there have been changing reasons or indications from cultural, traditional, religious and currently medical, and it has vehemently been criticized by some individuals for different reasons and in different countries. Emergency of new diseases particularly Human Immunodeficient virus (HIV) has brought the ancient procedure back on spot light, this has come as a result of recent studies which have demonstrated that it does not only reduces significantly the rate of HIV infection, as well as penile cancer and cervical cancer. This has lead to massive male circumcision campaigns in areas with low prevalence of circumcision. On the other hand the socio-cultural and sexual aspects of male circumcision have been studied but often ignored. This article will therefore increase awareness of male circumcision and the increasing roles with time, recommend up scaling of medical male circumcision and possible safe circumcision training to tradition circumcisers.
\end{abstract}

Keywords: male circumcision, prevalence, socio-culture, religion, disease prevention

\section{Introduction}

Male circumcision, a complete removal of male foreskin, has been practiced in many societies since antiquity. The earliest evidence of male circumcision was discovered in Egyptian tombs aged more than 4000 years (Israelistes, 1993). The reasons for this procedure have positively metamophormosed with changing societies and time and they include traditions, religion, hygiene and more recently medical problems such as cervical and penile cancers and Human Immunodeficiency Virus and the related complications (WHO, 2007).

Male circumcision also routes in various religious scriptures and history. For instance, since Abraham's the Jews have taken this procedure as a religious mandate and most Jews in contemporary World tend to circumcise (Israelistes, 1993). Some scholars have suggested that, Jews and followers of Judaism probably adopted circumcision to make penile hygiene easier in the hot, sandy climate but also as rite to passage into adulthood and as form of blood sacrifice (Lauman \& Masi, 1997; Schenker \& Gross, 1997). Christianity also provides an insight on the history of circumcision. In the earliest times of Christianity, circumcision was considered to be divine part of purity. Today with emergency of evangelical Christianity not all agree with this concept, although some especially those who abide to and strictly follow the early Christianity principles still consider circumcision as part of purity (WHO, 2007). On the part of Islamic religion, male circumcision has remained to be an obligation despite that the practice isn't mentioned in the Holy Quran. The religious base of circumcision on Islamic understanding is founded in the Abraham covenant. To-date, it is believed that Muslims who are not circumcised are not allowed to pilgrimage in Mecca, as uncircumcision is considered unhygienic (Lufti, 1998).

Ethnic routes of male circumcision are also obviously been seen in various ethnic groups. The procedure has been successfully practiced and transferred from one generation to another for many years among the Maasai in Northern Tanzania (Kilima et al., 2012). However in some of the circumcising communities, Mwita et al. (2009) suggested that traditional and religion

\footnotetext{
* Correspondence: Dr. Masumbuko Mwashambwa; E-mail: masuyt@yahoo.co.uk
} 
influences may have converging roles in male circumcision such that, the practice varies from one group to another depending on the prevalent religion.

\section{Prevalence of circumcision}

The global prevalence of male circumcision in individuals aged above 15 years is estimated to be about 30-33\% (Lauman \& Masi, 1997; WHO, 2007). About 70\% are estimated to be Muslims living in Asia, Middle East, and North Africa, and non-Muslim male contribute only about 13\% (WHO, 2007). Madagascar, Ethiopia, Angola, Democratic Republic of Congo and Nigeria have the highest rate (>90\%) of male circumcision in Africa. West and North African countries have higher prevalence than Southern African countries. In East and Central Africa, Kenya has the highest prevalence ( $84 \%$ ) followed by Tanzania (70\%) while Burundi, Rwanda and Uganda have very low prevalence of male circumcision (WHO, 2007, 2009; Mwita et al., 2009).

In Tanzania circumcision has traditionally been practiced in some ethnic groups for many pre-colonial years. However, the traditional practice was later negatively influenced by colonial rulers and missionaries (Nnko et al., 2001). This therefore created the so called none-circumcising belt or zone which stretches from west and southern parts of Lake Victoria through inland central Tanzania to south-western Tanzania. The prevalence of circumcision in this zone is between $26-69 \%$. On the other hand coastal and central Tanzania has remained a circumcising belt with a prevalence of circumcision of up to $80 \%$ (THMIS, 2004).

\section{Male circumcision techniques}

\section{Traditional male circumcision}

In traditional male circumcision a practitioner with no formal medical training and whose coverage and safety precautions are unclear does the procedure (Wilken et al., 2009). In most ethnic communities, the traditional male circumcision is usually done in form of a staged ceremony; starting with preparation stage, which then leads to the actual circumcision. This is then followed by a seclusion period in which the participants are confined in a specially prepared area, during which wound is left to heal, and finally reintegration stage in which the participants join the community (WHO, 2009). Most tradition circumcision practitioners in some parts of Africa indicate that they use a sharp knife or razor specifically prepared for this purpose. There are neither specific antiseptics nor antibiotics used and there are no analgesics used (Vincent, 2007). The practitioners and the societies believe that boys who are circumcised without analgesics are braver and stronger; and associate the use of analgesia with cowardliness and weakness on the part of the boy (Vincent, 2007).

\section{The practice in Tanzania}

In Tanzania, there hasn't been any study which has established the actual traditional male circumcision practices. However and it is believed that, the technique varies from one ethnic group to another (Kilima et al., 2012). This is reflected by the extent of removal of foreskin and on the part removed whether ventral or dorsal. For example it has been witnessed that Gogo tribe in central Tanzania circumcise in such a way that a flap of foreskin is folded back under the ventral aspect of the penis to make a small swelling considered to have sexual functions (Kilima et al, 2012). Maasai on the other hand leave a hanging flap of foreskin on ventral aspect of the shaft of the penis, which is also considered to increase female stimulation during coitus and in other ethnic groups the foreskin is completely removed (Kilima et al, 2012). As indicated earlier, in traditional male circumcision neither anaesthesia nor analgesics are used with aim of testing bravery, endurance and strength of the participants. Among the Kurya of northern Tanzania, the circumcision ceremony is done early in the morning to achieve some degree of anaesthesia and 
probably to prevent to some extent haemorrhage, as cold causes vasoconstriction (Chotani et al., 2000).

\section{Safety of traditional male circumcision}

There have been very few studies to assess complications associated with male circumcision such as wound, bleeding, obliteration of urethral opening, blood borne infections and death (Myers et al., 1985; Crowley \& Kesner, 1990; Mayatula \& Mavundla, 1997; Khalifa, 2000; Ahmed et al., 1999). Most of these studies have a range of limitation which makes comparison difficult (WHO, 2009). In one systematic review of studies done in East and Central Africa, Wilken et al. (2009) reported a complication rate of $35 \%$ and $48 \%$ and mortality rate of $0.2 \%$. In the same study, the commonest causes of hospitalization following traditional circumcision was wound infection, incomplete circumcision requiring re-circumcision and delayed wound healing. One study has reported loss of glans penis through either gangrene or amputation (Magoha, 1999).

\section{Medical circumcision}

There are many techniques used in male circumcision in medical world. The first one uses special circumcision rings of various made of either metal or plastic. The ring is usually placed around the circumference of the foreskin, and slowly but steadily compresses the blood supply to the distal part of the foreskin and therefore causes necrosis and sloughing and therefore achieving circumcision. It is a bloodless procedure which does not require anaesthesia, sutures, or a sterile setting, and it can be performed well by a non-surgeon after a brief training. The second type is an open method in which one has to be taken into a theatre and therefore requires sterile technique, anaesthesia, antibiotics and other pre and post operative care. The prepuce is then excised around the glans and sutures placed to achieve haemostasis. Studies have indicated that, although the former takes short time it commonly leads to delayed healing when compared to the later (Mutabazi et al., 2012). Another obvious and probable disadvantage of rings is its availability in most developed countries. The reported complication rate in individuals who underwent medical circumcision varies from one study to another and it ranges from $0.2 \%$ to $5 \%$ (Moses et al., 1998; Magoha, 1999; Khalifa, 2000).

\section{Socio-cultural aspects of circumcision}

\section{Reasons for circumcision}

One of the main reasons which have prominently been cited for traditional male circumcision is passage of rite to adulthood. In most ethnic groups traditional male circumcision is done as a way of maintaining cultural identity and perpetuating the traditions (WHO, 2009). Most ethnic groups do circumcise their young at around puberty, although the actual age can range from 6 to 53 years depending on the ethnic group or country (Rashid et al., 2009; WHO, 2009; Wilken et al., 2009). The procedure also aims at assessing and imparting strength and bravery, it is expected that during the act of circumcision, the participant should show strength by showing that he is not feeling any pain (Mwita et al., 2009). Equally during circumcision ceremonies, educational sessions are carried out to pass important knowledge to the youth, and therefore passage of ethnic traditions to each successful generation. In Malaysia, the government has incorporated into these ceremonies sexual and reproductive health and gender education to young (Rashid et al., 2009; WHO, 2009).

\section{Factors influencing circumcision}

In the contemporary world, various reasons have been shown to influence male circumcision. The commonest reasons include socio-economic status, education status and also urban dwelling (Nnko et al, 2001). It has been established that, the prevalence of male circumcision in men with high socio-economic status is usually high. Similar observation has been reported with secondary 
education and above (THMIS, 2004). Urban residents also tend to have higher prevalence of circumcision than their counterparts in rural areas, probably due to high socioeconomic and educational status. On other hand studies in Mwanza, Tanzania have also shown that if traditionally uncircumcising societies are mixed with traditionally circumcising societies, there is a positive shift towards circumcision, probably explaining the higher prevalence in urban (Nnko et al., 2001).

\section{Medical aspects of circumcision}

Over the recent years, there has been a vested interest over the role of circumcision in prevention of diseases. Recent evidences have shown that circumcision can prevent a number of infectious diseases, which include HIV (Weiss et al., 2000; Siegfried et al., 2003; Schenker \& Gross, 1997), cervical and penile cancer (Moses et al., 1998; Castellsague et al., 2002), urinary tract infections in childhood (Drain, et al., 2006), prevention of inflammation of the glans penis (balanitis) and the foreskin (posthitis), prevention of potential for scar tissue on the foreskin which may lead to phimosis (inability to retract the foreskin) or paraphimosis (swelling of the retracted foreskin resulting in inability to return the foreskin to its normal position), reduced risk of some sexually transmitted infections (STIs) such as chancroid and syphilis (Singh-Gewal et al., 2005; Weiss et al., 2006). It is also generally accepted that circumcision makes easier to clean the penis (Drain et al., 2006; WHO, 2007).

Recently studies have shown that not only males who are circumcised have lower risk of HIV infection than those who are not circumcised but also areas with high rate of circumcision have lower prevalence of HIV (Siegfried et al., 2003; Drain et al., 2006; Boyle \& Hill, 2011). It has also been established that uncircumcised males are 2-3 times more likely to be infected with HIV than their counterparts, and this effect is even greater in men with high risk of exposure to HIV (Drain et al., 2006). In a study in Uganda it has been shown that the protection rate is $51 \%-60 \%$ (Gray et al., 2007). These findings explain why countries with similar HIV risk behaviours have different pattern of HIV prevalence. For example, it has been determined that countries in SubSaharan Africa with circumcision rate above $80 \%$ have lower rate of HIV infection, while those with circumcision rate below $20 \%$ have high HIV infection (Weiss et al., 2000; Siegfried et al., 2003).

It has been also found that circumcised males have reduced risk of infecting their female partner with HIV (Drain et al., 2006). Both facts discussed above attests to the importance of male circumcision in prevention of this deadly disease. This has lead to various stakeholders to recommend male circumcision as a complementary but not a substitute method in HIV prevention. The efforts to upscale male circumcision should be upheld countries where there is an ongoing campaign on male circumcision (Francis et al., 2012).

There are biological explanations as to why uncircumcised males have higher risk of HIV infection than those circumcised. The inner lining of the foreskin has very high number of immune competent cells (Langerhans cells) which are the entry gate for HIV. This is facilitated by fact that the inner lining of the foreskin is very thin and therefore exposes the target cells to HIV. The foreskin is highly vascularised and therefore prone to minor injuries especially with dry intercourse and hence HIV infection. Studies have shown that uncircumcised males are more prone to infection with ulcer causing genital diseases which actually increases the risk of HIV infection (Drain et al., 2006).

Male circumcision has also been found to have a protective effect in cervical cancer to female partners and penile cancer in males. Both cancers are caused by a common viral agent known as Human papilloma virus (HPV). The reduction in HPV infection by circumcision (especially when done early in life) consequently leads to reduction in both cancers (Weiss et al., 2006). The penile cancer in western countries contributes below $1 \%$ of all cancers morbidity while in developing countries contributes to about 10\% (Castellsague et al., 2002). The fact that men 
who are not circumcised have great potential to be infected with HPV puts their female counterparts at increased risk of infection with this virus. The association between this virus and cervical cancer has been established beyond reasonable doubt (Muñoz et al., 2003; Snijders et al., 2006). HPV is a necessary factor in more than 90\% cases of cervical cancer, with types 16 and 18 being the most common isolates (Walboomers et al., 1999). The burden of cervical cancer in women in developing countries is irrefutably immense and therefore no efforts (including male circumcision) should be spared in combating it.

\section{Circumcision criticism}

Despite the health benefits of male circumcision, there are a lot of criticisms of whether circumcision can be universalized or not. Many critiques outline many reasons as to why circumcision should not be done to everyone, and some of these reasons are discussed. Most opponents of routine circumcision in children argue that children have right to remain with their intact body without being interfered by parents and practitioners involved in male circumcision until they are able to decide otherwise (Hinchley, 2007). They further argue that not only do children have the right to intact and unaltered body but also the right to have a peaceful, violence free begging of their journey to adult life and indicate that this procedure is violent, harmful, unnecessary and unethical to doctors who participate (Byle et al., 2000; Hinchley, 2007). Some use the worst terms such as birth without violence and amputation of normal skin to depict the cruelty of such practice in children (Marilyn \& MacRis, 1992).

It has been argued by opponents of circumcision that the attended risks of circumcision are quite high than most advertised benefits on medical grounds. The most common enlisted by complications by opponents of circumcision include scarring of the penis, loss of skin, stenosis of penile meatus/opening, abnormal penile curvature which may interfere with coitus, pain during coitus, loss of blood, psychological complications and even death (Hammond, 1999). The proponents (most of them scientists) however argue that the real medical risks are small (Marilyn \& MacRis, 1992).

Some studies have indicated that the human prepuce is one of the most erogenous organs in human body and that this organ contains very sensitive pressure and touch receptors and therefore play a very important role in sexual satisfaction to both the male and female counterparts (Sorrells et al., 2007). Some individual reports have also established that there may be diminished sexual performance and satisfaction on males who are circumcised as compared to their uncircumcised counterparts (Fink et al., 2002), although this have been refuted by proponents of male circumcision as having little evidence (WHO, 2007). In one study done in Denmark, women with circumcised partners tended to have more incomplete sexual needs, orgasm difficulties, lubrication insufficiency and dyspareunia when compared to women whose partners were not circumcised. In the same study men who were circumcised were likely to have more partners and experience more orgasm difficulties although the overall sexual function was similar (Frisch et al., 2011).

\section{Conclusion}

Despite many odds, circumcision seems to permeate throughout humankind from early ancient times to modern technologically developed world. It has been done for many reasons from religious, passage of rituals, traditional and hygienic reasons and more recently for prevention of diseases ranging from sexually transmitted diseases to potential childhood penile diseases. It can be done traditionally or medically, the former has many attending complications although there is scarce literature, while the later has many benefits with fewer complications. It therefore recommended that efforts to medically circumcise males be emphasized to complement on prevention strategies for HIV and other diseases. Training of traditional healers on safe 
circumcision should be considered; equally important is the need to utilize traditional circumcision ceremonies for reproductive health education. More research need to be done especially on claims that male prepuce is a significant role in sexual satisfaction.

\section{References}

Ahmed, A., Mbibi, N.H., Dawam, D. \& Kalayi, G.D. (1999) Complications of traditional male circumcision. Annals of Tropical Paediatrics 19, 113-117.

Boyle, G.J. \& Hill, G. (2011) Sub-Saharan African randomised clinical trials into male circumcision and HIV transmission: methodological, ethical and legal concerns. Journal of Law and Medicine 19, 316-334.

Boyle, J.B., Svoboda, J.S., Price, C.P. \& Turner, J.N. (2000) Circumcision of healthy boys: criminal assault? 1. Journal of Law and Medicine 7, 301-310.

Castellsague, X., Bosch, F.X., Munoz, N., Meijer, C.J., Shah, K.V., de Sanjose, S., Eluf-Neto, J., Ngelangel, C.A., Chichareon, S., Smith, J.S., Herrero, R., Moreno, V. \& Franceschi, S. (2002) International Agency for Research on Cancer Multicenter Cervical Cancer Study Group: Male circumcision, penile Human Papillomavirus infection, and cervical cancer in female partners. New England Journal of Medicine 346, 1105-1112.

Chotani, M.A., Flavahan, S., Mitra, S., Daunt, D. \& Flavahan, N.A. (2000) Silent alpha (2C)adrenergic receptors enable cold-induced vasoconstriction in cutaneous arteries. American Journal of Physiology - Heart Circulatory Physiology 278, 1075-1083.

Crowley, I.P. \& Kesner, K.M. (1990) Ritual circumcision (umkhwetha) amongst the Xhosa in Ciskei. British Journal of Urology 66, 318-321.

Drain, P.K., Halperin, DT., Hughes, J.P., Klausner, J.D. \& Bailey, R.C. (2006) Male circumcision, religion, and infectious diseases: an ecologic analysis of 118 developing countries. BMC Infectious Diseases 6, 172.

Fink, K.S., Carson, C.C. \& De Vellis, R.F. (2002) Adult male circumcision outcomes: effect on erectile function, penile sensitivity, sexual activity and satisfaction. Journal of Urology 167, 2113-2116.

Francis, J.M., Kakoko, D., Tarimo, E.A.M., Munseri, P., Bakari, M. \& Sandstro, E. (2012) Key consideration in scaling up male circumcision in Tanzania: views of the urban residents in Tanzania. Tanzania Journal of Health Research 14 (1).

Frisch, M., Lindholm, M. \& Grønbæk, M. (2011) Male circumcision and sexual function in men and women: a survey-based, cross-sectional study in Denmark. International Journal of Epidemiology 40, 1-15.

Gray, R.H., Kigozi , G., Serwadda, D., Makumbi, F., Watya, S., Nalugoda, H., Kiwanuka, N., Moulton, L.H., Chaudhary, M.A., Chen, M.Z., Sewankambo, N.K., Wabwire-Mangen, F., Bacon, M.C., Williams, C.F.M., Opendi, P., Reynolds, S.J., Laeyendecker, O., Quinn, T.C. \& Wawer, M.J. (2007) Male circumcision for HIV prevention in men in Rakai, Uganda: a randomised trial. Lancet 369, 657-666.

Hammond, T. (1999) A preliminary poll of men circumcised in infancy or childhood. BJU International 83 (Supplement 1), 85-92.

Israelistes, J.P. (1993) In: P. Israelites: A History of the Jews. Phoenix Press, London. 37.

Hinchley, G. (2007) Is infant male circumcision an abuse of the rights of the child? Yes. BMJ 335, 1180.

Khalifa, S. (2000) Implications of the protective effect of male circumcision against HIV: A review of male circumcision procedures currently used in Africa and their safety. MSc Dissertation, London School of Hygiene and Tropical Medicine, London, England. .

Kilima, S.P., Shayo, H.E., Msovela, J., Senkoro, K.P., Mayala, B.K., Mboera, L.E.G. \& Massaga, J.J. (2012) The potential of involving traditional practitioners in the scaling up of male 
circumcision in the context of HIV prevention in Tanzania. Tanzania Journal of Health Research 14 (1).

Lauman, E.O. \& Masi, C.M. (1997) Circumcision in United States: prevalence, prophylactic effects and sexual practice. JAMA 277, 1052-1057.

Lutfi, A.M. (1996) Islamic ruling on male and female circumcision. World Health Organization.

Magoha, G.A. (1999) Circumcision in various Nigerian and Kenyan hospitals. East African Medical Journal 76, 583-586.

Marilyn, M. \& MacRis, D. (1992) Circumcision: A Medical or a Human Rights Issue? Journal of Nurse-Midwifery 37, 87-96.

Mayatula, V, \& Mavundla, T.R. (1997) A review on male circumcision procedures among South African blacks. Curationis 6-20.

Moses, S., Bailey, R.C. \& Ronald, A.R. (1998) Male circumcision: assessment of health benefits and risks. Sexually Transmitted Infections 74, 368-373.

Muñoz, M., Bosch, F.X., de Sanjosé, S., Herrero, R., Castellsagué, X., Shah, K.V., Snijders, P.J.F. \& Meijer, C.J.L.M. (2003) Epidemiologic classification of human papillomavirus types associated with cervical cancer. New England Journal of Medicine 348, 518-527.

Mutabazi, V., Kaplan, S.A., Rwamasirabo, E., Bitega, J.P., Ngeruka, M.L., Savio, D., Karema, C. \& Binagwaho, A. (2012) HIV prevention: male circumcision comparison between a nonsurgical device to a surgical technique in resource-limited settings: a prospective, randomized, nonmasked trial. Journal of Acquired Immune Deficiency Syndromes 61, 4955.

Mwita, W., Mwanga, J., Mosha, J., Mshana, G., Mosha, F. \& Changalucha, J. (2009) Situational analysis for male circumcision in Tanzania: Final report. National Institute for Medical Research 30-33.

Myers, R.A., Omorodion, F.I., Isenalumhe, A.E. \& Akenzua, G.I. (1985) Circumcision: its nature and practice among some ethnic groups in southern Nigeria. Social Sciences and Medicine 21, 581-588.

Nnko, S., Washija, R., Urassa, M. \& Boerma, J.T. (2001) Dynamics of male circumcision practices in northern Tanzania. Sexually Transmitted Infections 28, 214-218.

Rashid, A.K., Swee-Ping, T. \& Narayan, K.A. (2009) Traditional male circumcision in a rural community in Kedah, Malaysia. IeJSME 3, 19-23.

Schenker, I. \& Gross, E. (1997) Male circumcision and HIV/AIDS: convincing evidence and the implication for the state of Israel. Harefuah 146, 957-963.

Siegfried, N., Muller, M., Deeks, J.J. \& Volmink, J. (2003) Male circumcision for prevention of heterosexual acquisition of HIV in men. Cochrane Database Systematic Review 3:CDo03362.

Singh-Grewal, D., Macdessi, J. \& Craig, J. (2005) Circumcision for the prevention of urinary tract infection in boys: a systemic review of randomised trials and observational studies. Archive Diseases in Childhood 90, 853-858.

Snijders, P.J., Steenbergen, R,D., Heideman, D.A. \& Meijer, C.J. (2006) HPV-mediated cervical carcinogenesis: concepts and clinical implications. Journal of Pathology 208, 152-164.

Sorrells, M.L., Snyder, J.L., Reiss, M.D., Eden, C., Milos, M.F., Wilcox, N. \& Van Howe, R.S. (2007) Fine-touch pressure thresholds in the adult penis. BJU International 99, 864-869.

THMIS (2004) Tanzania HIV/AIDS and Malaria Indicator Survey 2003/04. Tanzania Commission for AIDS, Zanzibar AIDS Commission, National Bureau of Statistics, Office of the Chief Government Statistician, \& Micro International Inc.

Vincent, L. (2007) Male circumcision policy, practices and services in Eastern Cape Province of South Africa. Case study.

Walboomers, J.M., Jacobs, M.V., Manos, M.M., Bosch, F.X., Kummer, J.A., Shah, K.V., Snijders, P.J., Peto, J., Meijer, C.J. \& Muñoz, N. (1999) Human papillomavirus is a necessary cause of invasive cervical cancer worldwide. Journal of Pathology 189, 12-19. 
Weiss, H.A., Thomas, S.L., Munabi, S.K. \& Hayes, R.J. (2006) Male circumcision and risk of syphilis, chancroid and genital herpes: a systematic review and meta-analysis. Sexually Transmitted Infections 82, 101-109.

Weiss, H.A., Quigley, M.A. \& Hayes, R.J. (2000) Male circumcision and risk of HIV infection in subSaharan Africa: a systematic review and meta-analysis. AIDS 14, 2361-2370.

WHO (2007) Male circumcision: global trends and determinants of prevalence, safety and acceptability. World Health Organization, Geneva.

WHO (2009) Traditional male circumcision among young people: a public health perspective in the context of HIV prevention. World Health Organization, Geneva.

Wilcken, A., Keil, T. \& Dick, B. (2009) Traditional male circumcision in eastern and southern Africa: a systematic review of prevalence and complications. Bulletin of the World Health Organization 88, 907-914. 